\title{
EL INDIVIDUO "MULTIMOTIVACIONAL" DE AMARTYA K. SEN: LA TEORÍA ECONÓMICA DESDE EL TERCER MUNDO
}

\author{
Oscar J. Urrutia San Juan \\ Universidad de La Rioja
}

\begin{abstract}
RESUMEN: Amartya K. Sen considera que es el grado de ejecución de las distintas capacidades del individuo y la posibilidad factible de llevarlas a término, lo que define no solamente su actividad y situación, sino además, el grado de desarrollo de la sociedad de la que es miembro. En otros términos, para Sen el individuo es 'multimotivacional' en sus metas vitales, y no únicamente motivado por la felicidad utilitarista. Esta concepción tiene consecuencias de largo alcance en relación, primero, con la democracia como principio político que mejor puede garantizar la continuidad del debate público informado y la expansión de las capacidades individuales; segundo, con la variabilidad de los resultados del mercado como mecanismo de asignación en términos de capacidades; y tercero, con la utilización de las capacidades individuales como técnica de justicia comparativa que podría formar parte de una teoría de la justicia global.
\end{abstract}

Palabras clave: Capacidades, agencia, democracia, justicia, mercado.

\section{AMARTYA SEN'S VISION ON THE COMPONENTS OF HUMAN WELL-BEING IN SOCIETY}

ABSTRACT: Amartya K. Sen's vision is that it is the extent to which the various individual capabilities are achieved, and the actual possibility to achieve them, what defines not only each person's activity and situation, but also the level of development of the society that she is a member of. In other words, a person is 'multimotivated' by her various goals in life, and not only by utilitarian happiness. This vision has far-reaching consequences in relation first with democracy as the best political principle to guarantee an ongoing informed public debate and the expansion of individual capabilities; second, with the variability in the results of 
the market as an allocation mechanism when considering capabilities, and third, with the use of individual capabilities as a technique of comparative justice that could become a part of a comprehensive theory of justice.

Keywords: Capabilities, agency, democracy, justice, market.

\section{Amartya K. Sen y el individuo 'multimotivacional': la teoría económica desde el Tercer Mundo.}

En el presente artículo vamos a estudiar la aportación realizada por Amartya K. Sen, que se enfrenta a la consideración del individuo como 'unimotivacional $^{\prime 1}$ en su conducta social. Arrancando de su examen de fenómenos relacionados con el desarrollo, como las hambrunas en su propio país, así como de las condiciones bajo las cuales se podría subsanar el problema en las reglas de elección social detectado por Arrow, Sen articulará todo un nuevo esquema para evaluar el bienestar y el desarrollo sociales, basándose en un nuevo concepto de desarrollo personal entendido como la libertad del individuo para lograr vivir una vida que le autorrealice. Sen fundamenta esta innovadora definición de desarrollo personal sobre una renovada visión del individuo que supera el monismo informacional del individuo 'unimotivacional' preconizado por la economía convencional' $^{2}$ y que denominamos por ello 'multimotivacional'.

\section{Breve aproximación a la obra de Amartya K. Sen}

Amartya Kumar Sen (Santiniketan, India 1933), Premio Nobel de Economía en 1998, posee una dilatada carrera que se ha visto reflejada en una muy extensa obra, cuya trayectoria arranca en la década de 1960 con trabajos sobre la Teoría de la Elección Pública, entre los que destaca su estudio de las excepciones al Teorema de Imposibilidad de Arrow.

1. Calificamos de 'unimotivacional' el concepto de individuo con el que opera la economía convencional -entendida ésta como la ciencia económica generalmente admitida como válida y como tal enseñada en universidades y demás instituciones de educación superior- porque ésta interpreta su conducta como guiada absolutamente y en todo momento por un único criterio de utilidad o placer personal, que además ha llegado a ser considerado como relacionado con el mayor o menor grado personal de disponibilidad material. Este monismo informacional sobre las aspiraciones vitales del individuo es lo que denominamos 'unimotivacional'.

2. Adoptamos la expresión 'economía convencional' como traducción de la expresión en inglés 'mainstream economics', de uso corriente en la literatura actual para referirse al conjunto de enfoques económicos definido arriba. 
Posteriormente habría que destacar su interés por la problemática e irregularidades del desarrollo, concluyendo que las crisis alimentarias se deben no a la escasez de alimentos, sino principalmente a distorsiones en los mecanismos de distribución de los mismos. Decidido defensor de las libertades políticas de la ciudadanía, arguyó que dichas crisis alimentarias eran menos probables en regímenes democráticos por su necesidad de reaccionar antes y más de acuerdo con las necesidades de la sociedad.

La identificación de las anomalías del desarrollo económico arriba indicadas le hizo investigar las bases de dicho desarrollo, Ilegando a la noción de capacidad asociada a la libertad positiva como fundamento del mismo ${ }^{3}$. Así, el pensamiento de Sen ha puesto en cuestión la motivación única del interés propio en la conducta individual sostenida por la economía convencional, además de proporcionar un enfoque renovado de aspectos fundamentales en la economía del bienestar como la justicia, la equidad y la regla de la mayoría.

Por último, destaquemos la decisiva influencia de las aportaciones de Sen acerca del desarrollo humano arriba reseñadas en la elaboración del Informe sobre el Desarrollo Humano ${ }^{4}$, elaborado por el Programa de Naciones Unidas para el Desarrollo ${ }^{5}$. En particular, destaca su influencia en el concepto de desarrollo, y por consiguiente, en los instrumentos escogidos para medirlo en distintas zonas del mundo, los cuales están centrados en la evolución de los fines y los medios del desarrollo, como materialización del enfoque de las capacidades $^{6}$.

\section{Del concepto de desarrollo como libertad al de individuo 'multimotivacional'}

Seguramente, el origen geográfico, cultural y social de Sen-distinto del de la mayoría de economistas relevantes en la configuración de la economía convencional- no fuera una mera coincidencia en la elección de sus primeros estudios sobre la pobreza, ni tampoco el que con ellos buscase poner de manifiesto la falta de identidad entre los conceptos de desarrollo y crecimiento económi-

3. El concepto de capacidad aparece desarrollado en el artículo de Sen "Equality of What?" de The Tanner Lecture on Human Values, Stanford University, 1979.

4. Human Development Report, publicación de carácter anual por parte del Programa de Naciones Unidas para el Desarrollo (PNUD) que se viene editando desde 1990, y cuyos índices tratan de dar una dimensión más adecuada del desarrollo humano en las distintas zonas del planeta.

5. El Programa de Naciones Unidas para el Desarrollo, establecido en 1965, es uno de los comités ejecutivos parte de la Asamblea General de Naciones Unidas, cuyos fines son el asesoramiento a países miembro sobre el acceso a tecnología, conocimientos y recursos para lograr mejoras en las condiciones de vida de la sociedad.

6. Sobre el tema puede verse PEDRAJAS HERRERO, M., El desarrollo humano en la economía ética de Amartya Sen, Servei de Publicacions, Universitat de Valencia, 2006, págs. 165166 y $269-270$. 
$\cos ^{7}$, además de realizar el planteamiento conceptual de una nueva medida personal y social del desarrollo, el bienestar y la libertad.

Comencemos por reseñar que Sen describe sus ideas anteriormente aludidas como "la perspectiva sobre los fines y medios del desarrollo centrada en la libertad" ${ }^{\prime \prime}$. Así, para resumir en pocas palabras la visión de Sen, digamos que contempla el rol de cada individuo al realizar su proyecto vital -por sí mismo y en cooperación con otros- utilizando y ampliando sus libertades, como el factor decisivo en la evolución de la sociedad en su conjunto.

Como guía preliminar al esquema seniano articulado en torno a las nociones de capacidad, funcionamiento y habilitación ${ }^{9}$ que examinaremos a continuación, es necesario, no obstante, realizar una serie de aclaraciones en relación con la idea general que Sen tiene sobre el estado del individuo.

\subsection{El estado del individuo}

Sen circunscribe su análisis del estado del individuo a las consecuencias que para el mismo tiene formar parte e interactuar con una determinada sociedad en un determinado tiempo.

Sen concibe el estado individual de un ser humano como una variable constituida por dos componentes relacionados entre sí, a saber:

- Primero, el componente de Agencia: Para Sen, este componente incluye todas las metas y valores vitales que la persona valora positivamente y persigue, tengan o no relación directa con su Bien-estar ${ }^{10}$ personal, que explicamos seguidamente. En este componente de Agencia, Sen incluye aspectos relevantes para el individuo de orden inmaterial y cualitativo, relacionados no solamente con el individuo en sí, sino también con la sociedad, el género humano, el medio ambiente, la ética y la moral, o la política, por citar algunos. Téngase en cuenta, además, lo siguiente:

- Que dicho componente de Agencia incluye los aspectos citados antes independientemente del grado de implicación personal directa en la

7. KUKLYS, W., Amartya Sen's Capability Approach. Theoretical Insights and Empirical Application, Springer-Verlag, Berlin, Heidelberg, 2005, pág. 9.

8. SEN, A.K., Development as Freedom, First Anchor Books, New York, 2000, pág. 53.

9. Seguimos en la traducción del término inglés 'Entitlements' al profesor CEJUDO CÓRDOBA en la elección del término castellano de 'Habilitaciones' por parecernos adecuadas las razones con que argumenta dicha opción en su artículo "Capacidades y Libertad. Una aproximación a la teoría de Amartya Sen", Revista Internacional de Sociología, Vol. LXV., no 47, Mayo-Agosto, 2007, pág 11, nota 1.

10. Traducimos este concepto de Sen ('well-being') como 'Bien-estar' para resaltar la diferencia con la idea más difundida y denotada por la palabra 'bienestar' (del inglés welfare), que es un concepto referente a aspectos materiales e inmediatos al receptor de los mismos. Así, el 'well-being' de Sen constituye un concepto más amplio que el de 'welfare', al cual incluye. 


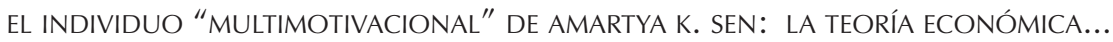

consecución de la meta de que se trate. En este sentido, hay que distinguir entre la Agencia propia directa, la Agencia propia indirecta, y la Agencia de otros. La Agencia propia directa sería aquélla en la que el individuo directamente es protagonista activo de un logro, y la Agencia propia indirecta sería aquélla en que el individuo influye en otros para que algo que valora sea conseguido (piénsese en la votación de un representante parlamentario de la circunscripción electoral del individuo, que vota a favor de una ley porque conoce el sentir mayoritario de sus electores). Por último, la Agencia de otros englobaría los casos en que un determinado logro valorado por el individuo es realizado porque otros han actuado como agentes, y no hablaríamos de verdadera Agencia por parte del individuo.

- Que el componente de Agencia se produce -esto es, que el individuo es agente- siempre y cuando el individuo adopte libre y reflexivamente la decisión de realizar alguna acción que contribuya directa o indirectamente al logro de dicha meta ${ }^{11}$. Así, el componente de Agencia, tal y como Sen lo concibe, depende más de la implicación del individuo agente que del propio logro de la meta.

- El concepto de Agencia implica el concepto seniano de libertad como facultad positiva -libertad efectiva para ser o hacer- más allá de la libertad negativa liberal entendida como ausencia de obstáculos o trabas para llevar a cabo una acción.

- Este componente resulta imprescindible -mediante la Agencia colectiva- para explicar sociedades tan complejas como las contemporáneas, donde la mediatización y burocratización de los mecanismos de acción social -además de los sistemas de democracia representativason de tal extensión y profundidad.

- Y segundo, el componente de Bien-estar: Sen considera este componente como el conjunto compuesto por todas las posiciones sociales de que disfruta el individuo, situaciones y acciones sociales que experimenta, y que están relacionadas directamente con su bienestar personal material en sentido amplio. Quedarían aquí englobados aspectos como cualificaciones profesionales y personales, la salud individual, o la disponibilidad de bienes y servicios, entre otros.

En contra de lo que pudiera parecer, ni el componente de Agencia es el único de carácter activo, ni el que hemos Ilamado de Bien-estar es el componente de carácter pasivo. No nos hallamos en un entorno utilitarista o de economía convencional en el que el bienestar es una sensación pasivamente experimentada al alcanzarse la satisfacción de las preferencias del individuo. No se trata ya de

11. SEN, A.K., Op. cit., 2000, págs. 18-25. 
una disquisición entre actividad y pasividad, sino más bien entre el ser humano -individual o colectivamente-que decide sobre algo y el ser humano -individual o colectivamente- como depositario u objeto de una decisión de otros sobre algo, la cual asume.

De otra parte, cada uno de los componentes mencionados puede ser considerado a su vez desde dos puntos de vista. Desde el de su Logro o consecución por parte del individuo, lo que, como veremos, nos servirá para definir adecuadamente el concepto de 'funcionamientos'. Y desde el punto de vista de la Libertad -positiva- para intentar lograrlos; perspectiva ésta que también adoptaremos más tarde para definir el concepto de 'capacidades'.

En cualquier caso, cabe ya destacar en este momento el contraste entre incluir acciones humanas de tipo altruista, filantrópico, humanitario, benéfico o de compromiso con una causa, y el determinismo conductual de la economía convencional basado en el individuo 'unimotivacional' -movido únicamente por el interés personal más inmediato-.

\subsection{Las Habilitaciones}

Amartya K. Sen define las 'habilitaciones' como "el conjunto de cestas alternativas de bienes y servicios de las que una persona puede disponer en una sociedad mediante la utilización de la totalidad de derechos y oportunidades que tenga"12.

Como nota preliminar, hay que hacer notar el carácter descriptivo y no normativo de esta definición, por más que las habilitaciones deriven de los derechos legales, y no de la moral o de los derechos humanos. Así, en su conocido trabajo acerca de la pobreza y las hambrunas, Sen subraya que es la ley lo que se interpone entre la disponibilidad de alimento y el derecho a alimentarse, y que por tanto, las muertes por inanición pueden resultar ser lo que él califica de 'legalidad vengativa'13.

El conjunto 'habilitaciones' de cada individuo constituye, desde el punto de vista sociológico, una relación de poder definida entre cada individuo, los demás y ciertos recursos, de forma que cada individuo posee un grado de poder sobre ciertos recursos que los demás han de respetar. Resaltemos que estas relaciones son de carácter normativo y se contemplan en su efecto económico, es decir, que no derivan de ningún planteamiento ético o moral, por más que aunque se trate de facultades personales positivas de acción respecto

12. SEN, A.K., Resources, values and development, First Harvard University Press, Cambridge, Massachusetts, 1997, pág. 30.

13. SEN, A.K., Poverty and Famines: An Essay on Entitlement and Deprivation, Clarendon Press, Oxford, 1981, pág. 166. 
a ciertos bienes o recursos, estas relaciones estén en línea con los derechos sociales y económicos considerados en el Estado del Bienestar ${ }^{14}$, que tienen un indudable matiz ético.

Así, en el ámbito de su estudio de la pobreza ${ }^{15}$ Sen enumera todos los orígenes legales posibles del alimento, que según él son cuatro, a saber, la 'habilitación de cultivar', la 'habilitación de comerciar', la 'habilitación de trabajar' y la 'habilitación de herencia y transferencia', las cuales engloban las posibilidades legales que puede tener cada individuo para -por una sola vía o por combinación de varias- procurarse alimento cultivándolo él, intercambiándolo por otro bien, comprándolo con su salario o recibiéndolo como herencia o transferencia. La crisis alimentaria sobrevendría cuando se produjera un descenso suficiente en los conjuntos de 'habilitaciones' de un grupo social o geográfico como para que su subsistencia no estuviera asegurada. Como acertadamente señala Cejudo Córdoba, el matiz normativo de las 'habilitaciones' hace que el ser titular de un derecho a subsidio constituya una 'habilitación', y que no sea ése el caso cuando se dependa meramente de la beneficencia pública ${ }^{16}$.

Sen, al abordar el concepto de 'habilitaciones' y su aplicación como instrumento analítico de las crisis alimentarias, adopta un punto de vista personalizado que se basa en analizar por qué determinados individuos no pueden acceder a un suministro adecuado de alimento. De todas formas, el enfoque de las 'habilitaciones' cubre también el origen 'malthusiano' de las hambrunas -debido al desfase entre población y disponibilidad- al contar entre los orígenes legales posibles del alimento que mencionábamos antes la 'habilitación para cultivar', razón por la cual es concebible una coyuntura de desaparición o colapso de dichas 'habilitaciones' que conduzca a una situación de privación de alimentos.

Más allá de lo que acabamos de explicar, el mismo Sen destaca las limitaciones que él observa en el concepto y aplicación de las 'habilitaciones' a la pobreza y las hambrunas, a saber:

- Que el consumo alimentario de una persona puede descender por debajo de lo que marcarían sus 'habilitaciones' debido a multitud de otras razones, como por ejemplo ignorancia, apatía, patrones de nutrición fijos, y también porque decidan hacerlo así para mejorar su expectativa de 'habilitaciones' en el futuro ${ }^{17}$ (racionamiento por temor de carencia futura, distribución desigual de alimento dentro de una misma familia, con prio-

14. CEJUDO CÓRDOBA, R., "Capacidades y Libertad. Una aproximación a la teoría de Amartya Sen", Revista Internacional de Sociología, Vol. LXV, nº 47, Mayo-Agosto, 2007, pág. 12.

15. SEN, A.K., Op. cit., 1981, pág. 2.

16. CEJUDO CÓRDOBA, R., Op. cit., 2007, pág. 11.

17. SEN, A.K., Op. cit., 1981, pág. 50. 
ridad a la nutrición de los adultos en edad de procrear por encima de la de ancianos y niños) ${ }^{18}$.

- La mortalidad en casos de hambre generalizada se debe frecuentemente a epidemias, lo cual no explica bien el enfoque de las 'habilitaciones'19.

- La posible imprecisión en la definición de las 'habilitaciones' por adoptar éstas formas legales más difusas que la propiedad como el usufructo, derechos de uso institucionales y propiedades en común.

- Aunque el enfoque de las habilitaciones es por definición de escala individual, Sen adopta frecuentemente escalas colectivas como pueden ser la familia, la clase o el grupo social. Evidentemente, cuando las 'habilitaciones' particulares de varios individuos, de una tribu, de un pueblo e incluso del Estado se solapan para un mismo recurso, suelen existir reglas que deciden la prioridad de los 'habilitados' a dicho recurso. Se ha intentado superar esta dificultad definiendo las que se denominan 'habilitaciones medioambientales' 20 , que si bien son reales, al no estar respaldadas por una estructura legal, dejan la 'habilitación' real individual al nivel resultante de factores como la autoridad, la influencia y la negociación entre los 'habilitados' inicialmente al uso de un recurso. El mismo Sen reconoce que, en el seno de la familia, pueden darse conflictos entre miembros a causa de 'habilitaciones' concurrentes sobre un mismo recurso o bien, y adopta para su análisis un punto de vista colectivo ${ }^{21}$ que parece invalidar el uso previo que él mismo realiza de las escalas individual, familiar y grupal casi indistintamente.

18. En este sentido, y a pesar de que Sen introdujo posteriormente el concepto de 'habilitaciones extendidas' para abarcar todas aquellas 'habilitaciones' legitimadas socialmente y no conferidas por mecanismos de mercado, lo cierto es que siguen siendo problemáticos la configuración y el ejercicio de las 'habilitaciones' en el ámbito intrafamiliar -básicamente por ser las 'habilitaciones' de tipo personal y tratarse de situaciones en las que no son las personas que deciden las que son afectadas por la decisión- no solamente en relación con ancianos y niños, sino también cuando tenemos en cuenta las diferencias por sexos, reflejadas en las asimetrías de mortalidad en el Sudeste Asiático en períodos de hambre.

19. Sen destaca que su enfoque de las 'habilitaciones', aplicado al caso de crisis alimentarias, no se centra en las muertes por inanición -causadas a menudo por epidemias asociadas a la desnutrición- sino más bien en el hambre propiamente dicha. Las epidemias pueden ser debidas a causas como migraciones masivas, fallo de condiciones sanitarias y otras causas, como en Darfur (Sudán) en los años 80.

20. Puede verse un interesante planteamiento de extensión de las 'habilitaciones' a estas circunstancias en LEACH, M. et al., Environmental Entitlements: a framework for understanding the institutional dynamics of environmental change, Discussion Paper 359, Institute of Development Studies, Brighton, 1997.

21. SEN, A.K., Gender and cooperative conflicts, en TINKER, I. (Editor), Persistent Inequalities: Women and World Development, Oxford University Press, New York, 1990. 
- La imprecisión de los derechos legales de propiedad que especialmente se da en zonas subdesarrolladas en las cuales no existe un ordenamiento jurídico suficiente para garantizar derechos de propiedad o regular las transacciones mercantiles. La relevancia de la asistencia recíproca o el trueque, así como que ocurran exacciones en especie y propiedades comunales en las que pueden darse simultáneamente propiedad compartida, control, acceso, derechos de uso y derechos a los frutos de un bien para un conjunto de individuos, pueden invalidar o complicar bastante este tipo de análisis.

- Puede ocurrir una alteración grave de las 'habilitaciones' de un grupo social en relación con su suministro alimentario debido a saqueos, sequías, o cualquier otra causa exógena. Estas causas exógenas, excluidas por Sen en su enfoque de las 'habilitaciones', pueden además ser intencionadas por cuanto pueden surgir beneficiarios y damnificados del suceso. En cuanto a los efectos posibles de una conflagración bélica sobre las 'habilitaciones' por alteraciones sobre mercados y economías locales, éstos pueden ser integrados y explicados mediante el esquema de las 'habilitaciones', al igual que ocurre en el caso de catástrofes de tipo natural. No ocurriría así con los efectos relacionados con saqueos, requisas, e incluso con estados de bloqueo o de sitio, que el análisis de las 'habilitaciones' no puede explicar por definición.

Retengamos por último que esta materialización de derechos y libertades civiles -se dispone de los medios materiales que permiten la ejecución de tales derechos, y el aprovechamiento de las oportunidades que pueden representar tales libertades- reflejada en las 'habilitaciones' es de carácter positivo, es decir, no se contempla como una ausencia de intromisión en la esfera privada del individuo -libertad negativa- sino que es conceptuada como la palanca de acción al servicio privativo del individuo respecto a una serie de recursos para lograr un fin.

\subsection{Los funcionamientos}

En este apartado vamos a estudiar en detalle el componente de Bien-estar en su vertiente de Logro, que es lo que Sen denomina 'funcionamiento' 22 . Evidentemente, en el concepto de 'funcionamientos' juegan un papel importante los medios de los que dispone una persona, las 'habilitaciones' de que disponga respecto a dichos medios, y sobre todo, lo que dicha persona hace con ellos. Para ilustrar esto, considérese el caso de un medio como la bicicleta que para un pa-

22. Del inglés 'functionings', modo o manera en que algo funciona o en que algo actúa. La elección de este término inglés por parte de Sen puede tener relación con la 'función' característica, típica, correcta o prevista para algo. Lo que sí es seguro es que Sen no presupone necesariamente voluntariedad del individuo en los funcionamientos que alcanza. 
ralítico no tiene un uso directo, para el ciclista aficionado es un medio de ocio y de salud, y para el ciclista profesional es, además, su empleo y fuente de ingresos.

Así, los 'funcionamientos' constituyen una variable compuesta de los Logros en materia de Bien-estar-relacionados directamente con el bienestar material en sentido amplio- que cada individuo consigue en su vida, y constatan empíricamente la realización del individuo en una determinada sociedad.

El profesor Cejudo Córdoba nos proporciona una valiosa ilustración del alcance de los 'funcionamientos' en su cita de Cervantes en la que Don Quijote, cansado de su vida de caballero andante, fantasea con un retiro a la vida pastoril $^{23}$. De su conjunto de 'funcionamientos' alternativos entre los que puede optar deriva el valor que tiene un 'funcionamiento' de vida al aire libre para él, en el que puede dedicarse a pasear, a disfrutar las puestas de sol o a leer; no sería ése el caso de un Sancho Panza, sin otras opciones que dedicarse a la vida de pastor para ganarse el sustento y sin formación para leer. Así, una medida del desarrollo individual y una cierta aproximación al grado de libertad individual pueden verse reflejadas en los 'funcionamientos', al considerarse los 'funcionamientos' alternativos entre los que uno y otro pueden optar.

Existen 'funcionamientos' que tienen carácter instrumental respecto a otros 'funcionamientos', tales como encontrarse bien de salud, lo cual abre otras muchas posibilidades, a pesar de que puedan necesitar reducir el grado de libertad del individuo para conseguir 'funcionamientos' alternativos que valore (vacunación obligatoria). En este sentido, la acción pública puede dirigirse a asegurar un nivel de un 'funcionamiento' determinado mínimo para el conjunto de la población -pensemos en la educación- con el fin de hacer posibles o accesibles otros muchos 'funcionamientos', o bien al menos para poner al individuo en la posición de poder realizar una opción consciente e informada acerca de su nivel futuro en dicho 'funcionamiento' o en otros.

Sin embargo, los 'funcionamientos' de un individuo no nos proporcionan una dimensión real de la libertad positiva -libertad operativa para ser u obrar- con que dicho individuo cuenta en su sociedad de referencia, ni del desarrollo personal, ni por consiguiente del desarrollo de la sociedad en su conjunto.

No obstante, es significativo que los 'funcionamientos' como noción resultan ser una plataforma firme a partir de la cual abordar el análisis del grado de desarrollo, bien sea en el nivel individual o en el social, porque dichos 'funcionamientos' son estados o acciones efectuadas, y no medios para realizar acciones o acceder a estados. Así sucede en el caso en diversos indicadores económicos, como el ritmo de crecimiento o la longevidad, que priorizan aspectos cuantitativos sobre aspectos cualitativos tales como el estado de salud a lo largo de la

23. CejUdO CÓRDOBA, R., Op. cit., 2007, pág. 15. 
vida, o el hecho de haber recibido un nivel determinado de educación. Algo análogo podría decirse de la ventaja de operar con los 'funcionamientos' individuales como variable, frente a hacerlo con la felicidad utilitarista, o incluso con los bienes primarios rawlsianos: éstos constituyen como máximo medios, pero en ningún caso fines en sí mismos o el propio contenido del proyecto vital del ser humano, como ocurre con los 'funcionamientos'. Por su parte, la felicidad utilitarista, como fin en sí mismo, puede estar asociada a malos 'funcionamientos', y estados de incomodidad o de insatisfacción pueden desencadenar 'funcionamientos' muy valorados.

En definitiva, los 'funcionamientos' le parecen a Sen una variable mucho más interesante que las anteriores por ser de fácil uso para identificar tanto situaciones de bienestar como de privación, además de ser mucho más intuitivo formarse una idea de cómo se encuentra una persona y el tipo de vida que lleva a través del grado de consecución que dicha persona está consiguiendo en los aspectos relativos a actividad y estado de su proyecto vital.

\subsection{Las capacidades}

El esquema seniano se cierra finalmente con un tercer concepto estructural: las 'capacidades'. Éstas, representan el Bien-estar en su vertiente de Libertad: son el conjunto de posiciones sociales, situaciones y acciones sociales que el individuo experimenta, en relación directa con su bienestar material en sentido amplio, pero consideradas desde el punto de vista de ser libre positivamente para realizarlas. Para Sen, las 'capacidades' son el resultado de una función, característica para cada individuo, que relaciona las distintas 'habilitaciones' de dicho individuo con el grado potencial de Logro que puede conseguir en su medio ambiente social para cada uno de sus objetivos en su Bien-estar ${ }^{24}$.

La dualidad entre 'funcionamientos' y 'capacidades' recuerda a la dualidad entre potencialidad y realidad aristotélicas, y así, el conjunto 'capacidades' de cada individuo nos proporciona información relevante acerca de:

- La variedad de 'funcionamientos' alternativos que son realizables por el individuo, y en cualquier caso, de qué 'funcionamientos' se trata.

- El grado de cada 'funcionamiento' elegido y realizado en comparación con el definido por la 'capacidad' específica relativa a ese 'funcionamiento'. El grado o nivel de 'funcionamiento' escogido puede depender de motivos inherentes al propio individuo, o a consideraciones de coste-beneficio. Efectivamente, una persona puede ser capaz de ser mejor o peor albañil porque valore también otros 'funcionamientos' alternativos que

24. CejudO CÓRDOBA, R., Op. cit., 2007, pág. 13. 
desea también ejecutar, o porque la asistencia a clases de albañilería le resulte más o menos cara en términos de dinero o tiempo, para alcanzar un determinado nivel de calidad como profesional.

La compresión del alcance exacto del concepto de capacidad seniano aconseja, no obstante, realizar algunas precisiones adicionales:

- Al definir la 'capacidad', Sen no se refiere a deseos o necesidades, ni a combinaciones de ambos. En efecto, si consideramos el caso de dos individuos, uno de los cuales se halla en un ayuno voluntario de protesta política, y el otro sencillamente no come porque no tiene qué comer, está claro que ambos comparten un mismo 'funcionamiento', pero solamente el activista político tiene la 'capacidad' de nutrirse adecuadamente, por más que decida no ejercerla -no 'funcionar'-. El deseo del activista político o la necesidad del hambriento son así independientes de las 'capacidades' de ambos.

- Tampoco se refiere Sen al hablar de 'capacidades' necesariamente a habilidades personales para algo. Para materializar una 'capacidad' específica en un 'funcionamiento', es concebible que ello venga facilitado por un rasgo o aptitud individual que confiera una mejor adaptación a la realización de ese algo, o por sus condiciones medioambientales.

- La 'capacidad' de Sen equivale a la oportunidad en el sentido de posibilidad factible y, en última instancia, de libertad sustantiva. Así, si un individuo es 'capaz' de alcanzar un estado o de realizar una acción:

- Existe la opción factible -convertible en 'funcionamiento' - para dicho individuo de alcanzar dicho estado o realizar esa acción.

- El que dicha opción sea factible -y pueda así convertirse en un 'funcionamiento' del individuo- a su vez depende de:

- Los rasgos personales del individuo, o bien, sus mejores o peores características cara a ser o desempeñar un 'funcionamiento' concreto. Pensemos en dos individuos, uno de los cuales tenga un cierto grado de impedimento físico, que aspiran a convertirse en conductores de taxi.

- Las condiciones externas de capacitación para el individuo cara a la opción referida, que no solamente se limitan a condiciones de no-intromisión. En el ejemplo anterior, hay que anticipar un probable coste efectivo más elevado para el individuo impedido porque su licencia especifique que deberá operar siempre con un taxi adaptado a su impedimento.

- Las 'capacidades' son susceptibles de gradación en diferentes niveles, al igual que ocurre con los 'funcionamientos'. De nuevo, las condiciones medioambientales, en combinación con los rasgos personales, las 'habilitaciones' disponibles y la consideración de costes y beneficios apareja- 
dos, pueden modificar al alza o a la baja una determinada 'capacidad' y su subsiguiente 'funcionamiento'. En nuestro ejemplo de los taxistas de nuevo, el individuo impedido, a la vista de los costes de obtener clases de conducción en un vehículo adaptado y de adquirir un taxi adaptado a su circunstancia, podría preguntarse si le merecen la pena los costes que le apareja ejercer de taxista.

Comparadas con los bienes primarios de Rawls o la satisfacción utilitarista, o incluso los 'funcionamientos', las 'capacidades' proporcionan una medida más ajustada de lo que un individuo puede llegar a ser o hacer en una determinada sociedad.

Así, la faceta de Agente del individuo configura a éste (en virtud del grado de libertad positiva existente en su medio social articulado en cauces institucionales de acceso libre al individuo que le permitan, individual o colectivamente, ejercer como Agente) como el elemento activo en la evolución de la sociedad, bien se trate de perseguir metas u objetivos que exclusivamente beneficien al propio sujeto -Bien-estar- o bien de beneficiar a los demás. Habrá individuos que utilicen su Libertad como Agentes exclusivamente para alcanzar Logros que 'cambien el mundo' en su favor; sin embargo, habrá otros que utilizarán su Libertad como Agentes para promover causas y conseguir Logros en favor de los demás, aun cuando ello vaya en detrimento de su propio Bien-estar individual.

\section{Reconsideración operada por Amartya K. Sen en la acepción económica de diversas nociones a la luz del enfoque de habilitaciones, capacidades y fun- cionamientos}

La estructura conceptual construida por Amartya Sen para evaluar la evolución del estado y actividad del individuo en el seno de una sociedad ha permitido nuevos enfoques en conceptos con trascendencia social y económica. A ellos vamos a referirnos sucintamente en este apartado, tratando de proporcionar una idea de las consecuencias derivadas del nuevo punto de vista aportado por Sen a cuestiones clásicas.

\subsection{La democracia}

La Agencia, ejercida individual o colectivamente, es la clave para engarzar la visión global de Sen sobre el individuo con la organización política de dicha sociedad de la que es miembro. Asimismo, la posibilidad factible -la libertad positiva- de ejercer la Agencia de modo asociado con otros permite salvar la dificultad que supone la mediatización dominante en sociedades contemporáneas, en las que a menudo el control directo de la vida individual no es ejecutable directamente por el propio individuo. En particular, la Agencia colectiva se adapta a la situación existente en las democracias representativas. 
Si adviniese una dictadura, y la faceta procedimental de la Libertad -la Agencia- quedase en suspenso, aun cuando el dictador tomase decisiones que el individuo libremente hubiera tomado $-y$ por lo tanto hubiera acaecido la consecución de fines valiosos para el individuo- como máximo habría mejorado el Bien-estar del individuo reflejado en un mayor conjunto 'capacidad', esto es, en más 'funcionamientos' alternativos posibles, o en 'funcionamientos' en un nivel más alto. Sin embargo, la dictadura supondría una lesión fatal y permanente de la Agencia, por lo que por un lado, en el mejor de los casos, nos haIlaríamos ante una expansión de la faceta de oportunidad de la libertad -'funcionamientos' y 'capacidades' - pero por otra, con una anulación de la faceta procedimental de la libertad -la Agencia-. En esta situación, habría que valorar que una dictadura, por tener vocación de continuidad, representaría una lesión permanente de la Agencia, mientras que su infalibilidad en medidas a favor de la población seguramente no sería sistemática.

Sen, en primer lugar, considera la democracia intrínsecamente buena porque capacita a los ciudadanos para participar en la política, y esto es una libertad que razonablemente es valiosa para el individuo. Así, la democracia y los derechos civiles y políticos tienen "importancia directa en la vida humana asociada con capacidades básicas" 25 .

Básicamente, la democracia es valiosa para Sen porque proporciona a cada ciudadano la Libertad de Agencia para promover sus intereses, y hace posible y realizable el Logro de Agencia cuando consigue que resulten elegidos sus candidatos y se realice la acción política deseada. Desde una perspectiva más global, hay que notar que un adecuado desarrollo de la sociedad proporciona la estructura social e institucional necesarias, facilita la aparición de cauces democráticos que garantizan la Libertad de Agencia y hace factible la oportunidad del Logro del individuo como Agente con el fin último de ser el árbitro de su propio destino ${ }^{26}$. Desde este punto de vista, la democracia permite el respeto a la dignidad de cada cual y su capacidad de autodeterminación ${ }^{27}$.

Existe, además, el matiz adicional de que la democracia fomenta la igualdad entre los miembros de la sociedad porque para todos garantiza el mismo nivel de protección y de oportunidad de ejercicio de Agencia -Libertad y Logro- y porque a todos proporciona el mismo nivel de Bien-estar en lo referido a aspectos básicos, cuya privación representaría una importante merma de nivel en dicho Bien-estar individual. En todo esto radica lo que Sen Ilama el valor intrínseco de la democracia ${ }^{28}$.

25. SEN, A.K., Op. cit., 2000, pág. 147.

26. Así, SEN, A.K., Op. cit., 2000, pág. 285.

27. Cfr. SEN, A.K., Op. cit., 2000, págs. 241-242.

28. Véase SEN, A.K., La démocratie des autres, Éditions Payot \& Rivages, Paris, 2005, págs. 65 y ss. 
Hay que valorar asimismo el valor instrumental que para Sen tiene la democracia, en el sentido de que es más sensible por definición ante una situación adversa de la ciudadanía o de parte de ella. Se puede esperar que por poco profunda que sea una democracia -que se quede en signos externos tales como el voto o la regla de la mayoría- o poco extendida -que no garantice la participación de todas las capas sociales-, siempre será más reactiva ante situaciones de privación que una dictadura o una tiranía benevolente ${ }^{29}$. En este sentido, podríamos hablar del poder protector de la democracia ${ }^{30}$, incentivado en sus gobernantes por el deseo de ser reelegidos.

Sen también argumenta lo que él denomina el 'valor constructivo de la democracia', es decir, la posibilidad que crea la democracia en términos de cauces procedimentales e institucionales que permiten el intercambio entre los ciudadanos para construir colectivamente el futuro de la sociedad en lo relativo a sus valores y a las prioridades entre los mismos: "Los derechos políticos y civiles, especialmente aquéllos relacionados con la garantía de libre diálogo, debate, crítica y disentimiento son fundamentales en los procesos de generación de elecciones informadas y conscientes. Estos procesos son cruciales en la formación de valores y prioridades, y no podemos, en general, tomar las preferencias como independientes del debate público, esto es, ajenas a si los debates y el intercambio se permiten o no." ${ }^{31}$, todo lo cual se articula alrededor del ejercicio de la elección pública.

Para todas las alternativas sociales posibles -incluida la decisión de quiénes y cómo deben realizar dichas elecciones- Sen plantea que se necesita previamente el que la sociedad en su conjunto esté informada, sea consciente y opine al respecto ${ }^{32}$. Además, ello forma parte, para Sen, de la democracia y de un ejercicio responsable y consciente de la elección pública ${ }^{33}$. En el mismo sentido, hay que subrayar la importancia que Sen concede al dinamismo del debate público sobre formación de valores y argumentos de moralidad ${ }^{34}$, producido porque los miembros de la sociedad aprovechen la oportunidad de participar en el mismo $^{35}$.

Para Sen, es así como puede fundamentarse una base socialmente sólida para definir y construir el desarrollo social, entendido como la expansión de las 'capacidades' mediante la ampliación de 'funcionamientos' alternativos posibles y la mejora en los niveles de los mismos en el futuro como objetivo de la sociedad. En realidad, Sen explica la democracia a la luz de las 'capacidades', inci-

29. Así, véase SEN, A.K., Op. cit., 2000, pág. 152.

30. SEN, A.K., Op. cit., 2000, pág. 43.

31. SEN, A.K., Op. cit., 2000, pág. 153.

32. SEN, A.K., Op. cit., 2000, pág. 30.

33. SEN, A.K., Op. cit., 2000, pág 110.

34. SEN, A.K., Op. cit., 2000, pág. 155-156.

35. SEN, A.K., Op. cit., 2000, pág. 329, nota 9. 
diendo en la importancia de los principios democráticos que garanticen la Agencia, con el fin de crear el respaldo social deliberativo y continuo a lo que él parece sugerir como el fin mismo de la sociedad a través del desarrollo, que es la expansión de las 'capacidades' -colectivas e individuales- de sus miembros. Desde este punto de vista, la democracia, entendida como la participación en las decisiones políticas y el ejercicio abierto de la elección pública, son tanto la base como el fin mismo del desarrollo ${ }^{36}$. Y se trata, en toda esta argumentación desarrollada por Sen, de la expansión de 'capacidades' - del desarrollo en definitiva- de una sociedad cuyos miembros escogen participativamente. Miembros que, evidentemente, no hay por qué presumir que en su totalidad busquen exclusivamente su Bien-estar; en otros términos, miembros que hay que presumir 'multimotivacionales'.

\subsection{La justicia}

Sen aplica su esquema operativo de las 'capacidades', que ya hemos examinado, a la idea de la justicia. La argumentación de dicha aplicación, como él mismo señala, está motivada y estructurada en gran medida por la teoría de la justicia como equidad de Rawls ${ }^{37}$, que, según él mismo indica, fue la obra que le hizo interesarse por este tema ${ }^{38}$. Hay que señalar, como nota previa, que Sen realiza consideraciones acerca de la justicia y de las distintas teorías existentes, sin por ello proponer él mismo una alternativa completa a las mismas. Sen argumenta a favor de teorías parciales que sean operativas en problemas concretos argumentando que una teoría de la justicia puede buscar la definición de principios básicos, sin por ello ser capaz inmediatamente de proveer soluciones a problemas cotidianos de justicia comparativa. Sin embargo, pueden concebirse teorías que sean capaces de detectar estas situaciones anómalas y de poder proporcionar claves para su corrección ${ }^{39}$.

Así, Sen hace gravitar toda su argumentación acerca de la justicia sobre el principio de racionalidad del ser humano. Sen cree que el ejercicio de la razón es el aliado imprescindible para formular juicios de tipo ético porque, ya desde el mismo procedimiento seguido para el examen de una determinada situación, la razón es la mejor garantía de la objetividad del resultado ${ }^{40}$.

El diseño de un procedimiento de investigación ética que asegure la objetividad puede ser bastante discutible, pero esto se puede también subsanar con un

36. SEN, A.K., Op.cit., 2000, pág. 291.

37. SEN, A.K., Bienestar, Justicia y Mercado, Ed. Paidós, Barcelona-Buenos Aires-México, 1997, pág. 109.

38. SEN, A.K., The Idea of Justice, The Belknap Press of Harvard University Press, Cambridge, 2009, pág. 52.

39. SEN, A.K., Op. cit., 2009, págs. 96-102.

40. SEN, A.K., Op. cit., 2009, pág. 40. 
examen adecuado de las materias subyacentes en toda situación que se pretenda enjuiciar desde el punto de vista ético ${ }^{41}$. Sen mantiene con Rawls y con Habermas que las soluciones objetivas pueden ser alcanzadas a través del ejercicio de la razón mediante el debate público de individuos bien informados y con apertura de miras a considerar racionalmente todos los argumentos.

Para Sen, no obstante, la imparcialidad en las teorías contractualistas de la justicia puede estar afectada por la predefinición de los llamados al debate público. Éste es el caso en la construcción del concepto de justicia realizado por Rawls a partir de su 'posición de origen' mediante el ejercicio de la ecuanimi$\mathrm{dad}^{42}$. En efecto, Rawls construye su idea de justicia a partir de lo que denomina la 'posición de origen', que es un estado imaginario de igualdad primigenia en la que los individuos interactuarían con ecuanimidad, es decir, una situación en la que "...nadie conoce su lugar en la sociedad, ni su clase o estatus social, ni su suerte en el reparto de activos naturales o capacidad, ni su inteligencia, ni su fuerza, ni nada por el estilo." 43 -bajo lo que denomina Rawls el 'velo de la ignorancia' - para acordar ecuánimemente los principios de la justicia y las instituciones básicas de gobierno de la sociedad, que Rawls considera únicos. Rawls, además, defiende la objetividad de este proceso limitando, desde su punto de vista contractualista, los participantes en el debate de la 'posición original': "...los términos ecuánimes de la cooperación social son concebidos y acordados por aquéllos involucrados en ella, esto es, por ciudadanos libres e iguales que nacieron en la sociedad donde viven" ${ }^{\prime 4}$.

En este último aspecto, Rawls cae, para Sen, en compartimentar una idea que, como la justicia, debería ser universalizable, siguiendo en ello a Kant. Sen, en cambio, destaca la posición más abierta y a su juicio acertada del contractualismo de Smith, en el sentido de que su mecanismo del 'espectador imparcial' -expuesto en su 'Teoría de los Sentimientos Morales' de 1759- está abierto a todo punto de vista, tanto se trate de los miembros del grupo social como de externos -por posición o por intereses- a dicho grupo social.

En favor de la imparcialidad abierta -universal- como requisito deseable de objetividad al construir una teoría de la justicia, Sen aduce también para ello razones de tipo consecuencial, por cuanto los resultados de la elección social de un grupo no se confinan al límite geográfico de ningún Estado, sino que siempre tienen consecuencias más allá de sus fronteras, repercutiendo en otros grupos sociales. Evidentemente, este mismo hecho es razón suficiente, en opinión de Sen,

41. SEN, A.K., Op. cit., 2009, pág. 42.

42. Del inglés "fairness". Preferimos el término castellano "ecuanimidad" al más frecuente de "equidad", por las connotaciones de imparcialidad más claras del primero, según las acepciones de ambos términos en el Diccionario de la R.A.E. XXII Ed.

43. RAWLS, J., A Theory of Justice, The Belknap Press of Harvard University Press, Cambridge, 2005, pág. 12.

44. SEN, A.K., Op. cit., 2009, pág. 127. 
para estar a favor de una imparcialidad abierta el alcance de la responsabilidad que deriva de la toma de posición implícita en toda elección pública ${ }^{45}$. Por más que esto pueda recordar el consecuencialismo propugnado por la ética utilitarista, Sen opina que la evaluación de las consecuencias de una elección debe ser tomada en cuenta ${ }^{46}$, señalando que lo que en este punto hace insatisfactoria la ética utilitarista es la amplia insuficiencia de criterios evaluadores de una situación social -que en este enfoque se reducían a la utilidad- lo que en su opinión constituye una base informacional insuficiente, como veremos a continuación.

Lo que ocupa a Sen en primer lugar es definir lo que él denomina la base informacional de la justicia, es decir, la definición y delimitación de toda aquella información de la que dependen los juicios de valor relativos a la justicia, en el supuesto de que la veracidad o falsedad de cualquier otra información no incluida en dicha base informacional antes mencionada no afecta directamente a la rectitud-imparcialidad y objetividad-del juicio de valor.

Así, y añadiendo el requisito de universalidad explicado antes, Sen considera que una base informacional adecuada descansa en la noción de libertad positiva, que incluye y amplía la libertad entendida como ausencia de intrusiones para realizar o ser algo -la libertad negativa-.

Entendida así la libertad, ésta es una facultad susceptible de valoración por parte del individuo a causa, en primer lugar, de su vertiente de oportunidad factible para intentar alcanzar los objetivos que puedan formar parte del proyecto vital de dicho individuo ${ }^{47}$. En segundo lugar, la libertad posee la vertiente de proceso, es decir, la relativa a la posibilidad real del individuo para poder elegir entre diversos cursos de acción o estados, especialmente si consideramos la variabilidad de los comportamientos individuales a lo largo del tiempo y las distintas maneras en que una misma meta puede ser alcanzada por distintos individuos. Así, la base informacional de la justicia es fundamentada por Sen en la 'capacidad' del individuo de hacer o ser lo que dicho individuo valore como deseable. En relación con la adopción de la 'capacidad' como base informacional de la justicia, Sen realiza las siguientes precisiones ${ }^{48}$ :

- Las 'capacidades' proporcionan visión informacional clara al juzgar y comparar situaciones generales de ventaja comparativa de unos individuos frente a otros. Sin embargo, las 'capacidades' no indican cómo utilizar esta información, ni cómo organizar la sociedad.

- Las 'capacidades' engloban diversos y muy distintos aspectos que conciernen a la vida humana porque el objetivo que persiguen es el de ser un índice de la calidad de la vida individual.

45. SEN, A.K., Op. cit., 2009, pág. 206.

46. SEN, A.K., Op. cit., 2009, págs. 217-218.

47. SEN, A.K., Op. cit., 2009, pág. 228.

48. SEN, A.K., Op. cit., 2009, págs. 232-234. 
EL INDIVIDUO "MULTIMOTIVACIONAL" DE AMARTYA K. SEN： LA TEORÍA ECONÓMICA...

- La perspectiva de las 'capacidades' contrasta con los tradicionales enfoques cuya base informacional son los medios -los bienes primarios de Rawls o los recursos de Dworkin- los cuales no son necesariamente en sí mismos los fines de un proyecto vital.

- La 'capacidad' supera la visión del 'funcionamiento' elegido por un individuo acerca de su calidad de vida por incluir la variedad y grado de funcionamientos alternativos factibles -la libertad positiva de vivir conforme a otras metas vitales-. Identificar la 'capacidad' al 'funcionamiento' elegido equivaldría a dar un valor nulo a proyectos de vida alternativos elegibles y a confundir lo observado con lo elegido.

- Las 'capacidades' crean un espacio para comportamientos individuales éticos basados en el deber de actuar o ser cuando se es capaz de realizar algo que puede mejorar la existencia de los demás. Pautas de conducta altruista, generosa o de compromiso con ideales filantrópicos ${ }^{49}$ encuentran así su espacio.

Sen argumenta asimismo que la igualdad, probablemente por sus connotaciones de no discriminación, por la necesidad de un consenso general en un principio de justicia aceptable para todos, y por las razones de imparcialidad, universalidad y objetividad citadas antes, seguramente sea un principio necesario para fundamentar cualquier teoría de la justicia ${ }^{50}$. Ahora bien, la cuestión crítica estriba en definir el parámetro o parámetros sobre los cuales aplicar dicha igualdad. Sen constata que focalizarse en la igualdad de un conjunto demasiado estrecho de parámetros necesariamente provoca distorsiones en la igualdad de otros parámetros también relevantes en la percepción de la idea de justicia. Por ello concluye que la igualdad es un principio con aplicación en múltiples dimensiones que han de resultar complementarias en la elaboración de una teoría de la justicia de tipo trascendental. El mismo Sen señala que la igualdad de 'capacidades' no podría constituir en ningún caso el criterio operativo único de una teoría de la justicia -trascendental o comparativa- porque solamente capta la faceta de oportunidad factible de la libertad positiva, y no los aspectos procedimentales de la misma -la Agencia-. Sin embargo, para Sen su enfoque es válido y útil como teoría parcial comparativa que ayuda a detectar situaciones injustas, y previsiblemente como parte integrante de una teoría trascendental de la justicia. Asimismo, principios como el de la libertad habrían de ser matizados y equilibrados frente a otras consideraciones de justicia social distributiva, según Sen, dentro de una teoría global de la justicia.

En cualquier caso, si nos atenemos al objetivo más modesto de diseñar una técnica comparativa de detección de desequilibrios sociales de justicia, y dada

49. FREIJEIRO VARELA, M., "¿Hacia dónde va la ciudadanía social?", Revista Andamios, Vol.5, no 9, Diciembre 2008, pág. 176.

50. SEN, A.K., Op. cit., 2009, pág. 293. 
la multiplicidad de circunstancias y de tipología de individuos, el enfoque de las 'capacidades', basado en un individuo movido o motivado por una multiplicidad de ideales, intereses y objetivos que valora racionalmente, que pueden cambiar a lo largo de su vida, y algunos de los cuales se relacionan directamente con su bienestar más inmediato -mientras que otros pueden obedecer a razones ajenas- ciertamente capta más y mejor las diversas características de los individuos en el desarrollo de su proyecto vital que otras propuestas alternativas, y proporciona además una visión más real de la libertad positiva de los individuos, habida cuenta de que la libertad como oportunidad factible es ampliamente considerada como otro ingrediente fundamental en una teoría trascendental de la justicia.

\subsection{El Mercado}

En relación con el mercado competitivo, la aplicación que Sen realiza de su enfoque de las 'capacidades' parte de la valoración que la llamada economía del bienestar -parte de la economía convencional- realiza del mecanismo del mercado en condiciones de competencia perfecta. Sen considera que cualquier argumentación en favor del mercado competitivo no puede prescindir de la evaluación de los resultados que tiene como mecanismo de asignación. En efecto, aun cuando las doctrinas de tipo liberal han reivindicado una serie de derechos fundamentales independientemente de los resultados sociales que su adopción pueda comportar en un entorno de mercado libre, dichos resultados sociales podrían resultar de una valoración ética bastante pobre ${ }^{51}$, y poner en cuestión la aceptabilidad general de dichos derechos.

En este sentido, la argumentación a favor del mercado competitivo realizada desde la economía del bienestar a través de los dos Teoremas Fundamentales de la Economía del Bienestar se ha venido basando en la aparente posibilidad que ofrece de utilizar el mecanismo del mercado competitivo para, una vez identificada una situación social de óptimo de Pareto, acceder a ella dejando operar al mercado en condiciones de libre competencia, y partiendo de una situación inicial determinada de asignación de recursos. En función de las imposibilidades de orden práctico, social y legal que pueden existir para redistribuir los recursos en una sociedad, además de los exigentes requisitos teóricos del modelo-ausencia de externalidades, ausencia de economías de escala, y otros- lo cierto es que este teorema del bienestar no garantiza, ni siquiera de forma restringida, la consecución de un óptimo social en sentido de Pareto que haya sido escogido previamente como óptimo social.

Frente a las propuestas de tipo liberal, Sen explica que, así como éstas han dado prioridad a la vertiente de la libertad como proceso, subrayando la impor-

51. SEN, A.K., Op. cit., 1997a, pág. 134. 
tancia de la libertad en sentido negativo -ausencia de intromisión en el ejercicio de derechos fundamentales- comparativamente han prestado escasa atención a la vertiente de la libertad como oportunidad real -que es lo que está en la base del enfoque de las 'capacidades' - con el peligro al que antes aludíamos de poder propiciar condiciones iniciales que desemboquen en equilibrios de mercado dudosamente aceptables desde el punto de vista ético. Por otra parte, si examinamos el mercado competitivo en relación con la libertad como proceso, hay motivos para creer que es un mecanismo coherente con dicho aspecto de la libertad por cuanto el mercado libre garantiza la autonomía en las decisiones y también la inmunidad contra las intrusiones, en gran parte por los propios supuestos del modelo teórico.

Para evaluar el mercado respecto a la libertad como oportunidad real de conseguir o de ser algo, lo cual el enfoque de las 'capacidades' está diseñado para captar, Sen se plantea la cuestión de los criterios según los cuales pueden valorarse las oportunidades reales -o bien los logros alternativos alcanzables- con que cuenta un individuo, así como qué son dichos logros. Para responder a lo primero, Sen concluye que no es solo el número de consecuciones alternativas con que cuente un individuo lo que influye en la valoración del grado de oportunidad real individual, sino más bien el que existan o se incluyan oportunidades cualitativamente mejor valoradas por el individuo ${ }^{52}$. En relación con la segunda cuestión planteada, la naturaleza de las oportunidades consiste, como ya se ha visto, en el conjunto capacidad' entendido como los 'funcionamientos' alternativos que un individuo puede conseguir, y que reflejan estados y acciones que dicho individuo valora.

El examen de Sen de la actuación dinámica del mercado competitivo hacia el equilibrio en relación con las oportunidades revela además que, por más que la situación de equilibrio resulte menos eficiente en términos de libertad como oportunidad que en términos de bienes (es decir, que el óptimo de Pareto no se alcanza en la misma medida que para los bienes), pueden producirse agravamientos en los problemas de equidad que pueden ocasionarse a pesar de estar en situación de óptimo de Pareto ${ }^{53}$. Este agravamiento puede provenir de la conjunción probable en un mismo individuo de que esté en desventaja para conseguir recursos y de que además esas mismas desventajas también se traduzcan en menos posibilidades de transformar dichos recursos en realizaciones valoradas de modos de vida. En otras palabras, aun cuando la deseable eficiencia en las preferencias de bienes que garantiza la situación de equilibrio en el mercado como mecanismo de asignación se produce en menor medida en términos de libertades, las posibilidades de desigualdad solo pueden aumentar.

52. SEN, A.K., Op. cit., 1997a, págs. 138-142.

53. La situación de óptimo de Pareto se produce cuando no es posible mejorar la situación de un miembro de un grupo social sin empeorar la de algún otro en relación con un criterio. 
Así, el análisis de la aplicación de las 'capacidades' al mercado revela que se mantienen las grandes dudas acerca del mismo como mecanismo de asignación en cuanto a la equidad de sus resultados, al depender éstos de las situaciones iniciales y de los propios supuestos de base del modelo teórico. Además, los resultados de asignación del mercado en términos de libertad como oportunidad real para los individuos muestran el riesgo de que el mercado competitivo acreciente la falta de equidad inicial.

De nuevo, el planteamiento de Sen, basado en una visión más amplia del ser humano en su interacción social, nos refleja las graves limitaciones que puede mostrar el mercado competitivo, no ya como medio para que el individuo obtenga bienes que maximicen su utilidad -perspectiva bienestarista de la economía convencional- sino para lograr los objetivos que valora en su vida, perspectiva ésta mucho más globalizadora e integradora, y por tanto, seguramente más cercana a la realidad.

\section{Conclusiones}

A partir del concepto de individuo subyacente en el pensamiento de Sen, y que hemos dado en Ilamar 'multimotivacional'-, a nuestro juicio cabría extraer las siguientes conclusiones:

1. Amartya K. Sen crea su enfoque relativo a la estructura motivacional del individuo a partir de sus reflexiones sobre la inadecuación entre crecimiento y desarrollo tras 1945. Su concepción se fundamenta sobre la base de que la vida plena y buena del individuo en sociedad puede analizarse atendiendo a, por una parte, el conjunto 'capacidad', el cual expresa todos los 'funcionamientos' alternativos posibles que dicho individuo tiene a su alcance realizar, o en otras palabras, todos los 'haberes y estares' alternativos que dicho individuo puede factiblemente experimentar, y por otra parte, atendiendo a la libertad positiva de ser Agente para promover consciente y voluntariamente metas y valores que considera valiosos. Aplicando estas nociones al análisis económico del individuo en sociedad, surgen visiones renovadas de conceptos clásicos como el bienestar, el mercado y el desarrollo, que invariablemente comparten la preocupación por el grado de cumplimiento del proyecto vital que cada sociedad, institución y proceso económicos son capaces de proveer para el individuo, lo que equivale a decir que comparten la preocupación por una eficiencia en la ampliación efectiva de la libertad positiva del individuo en su sociedad de referencia.

2. La concepción de Sen presenta puntos que nos recuerdan la ética de Aristóteles, ya que realmente se está apoyando sobre la relación peculiar existente entre la definición que realiza de los conceptos de 'capacidad' y de libertad. Dicha relación puede ser asociada con la 'potencialidad' aristotélica (dynamis) en el sentido del ser humano que vive la vida que puede factiblemente conseguir vivir. Así, la perspectiva del ser humano en su contexto social realizándose 
-ejerciendo sus funciones en tanto que ser humano- en el proyecto vital que conscientemente valora como deseable, es decir, con posibilidad factible de ser Agente -individual o colectivamente- orientado voluntariamente a fines diversos que le realizan, es un esquema que nos parece que responde al encuadre del individuo concebido por Aristóteles, y es capaz de juzgar sus acciones por pertenecer al ámbito de la ética. Por último, reiteremos que uno de los primeros motivos por los cuales surgió el enfoque de las 'capacidades' seniano fue el de medir la libertad real ejecutable del individuo para llevar a cabo su proyecto vital en el seno de su grupo social -o medir la autonomía del individuo para poder vivir la vida plena y feliz que preconizaba Aristóteles-.

3. La ampliación del horizonte analítico que el enfoque de Sen propone respecto al de la economía convencional, impone, entre otros, el estudio de la estructura institucional que pueda garantizar la libertad positiva de Agencia -individual y colectivamente- así como de los mecanismos sociales de elección pública y de formación de valores.

4. Sen postula su enfoque de las 'capacidades' como instrumento de detección y corrección de situaciones anómalas en términos de justicia comparativa, y como aportación útil en la construcción de una teoría transcendental de la justicia que mejore planteamientos precedentes. En relación con el mercado como mecanismo de asignación, Sen alerta sobre las potencialmente mayores faltas de equidad que puede producir en términos de 'capacidades', y por consiguiente, en la menor fiabilidad del mercado libre como instrumento único y autónomo de desarrollo y bienestar sociales entendidos como expansión de las libertades positivas del individuo para protagonizar su proyecto vital, y así, junto al resto de la sociedad, constituir la clave del progreso.

5. Al final, el planteamiento de Sen se ramifica a los ámbitos de la justicia, la ética, la política y, en general, las ciencias sociales, todo lo cual vuelve a imbricar a la economía con las demás Ciencias Sociales en muchos más aspectos que en el último siglo y medio, que es por cierto el ámbito que pensamos que naturalmente le corresponde a partir de la consideración detallada del ser humano como la molécula de la sociedad.

\section{Bibliografía citada}

CEJUDO CÓRDOBA, R., "Capacidades y Libertad. Una aproximación a la teoría de Amartya Sen", Revista Internacional de Sociología, Vol. LXV, no 47, Mayo-Agosto, 2007, pp. 9-22.

FREIJEIRO VARELA, M., "¿Hacia dónde va la ciudadanía social?", Revista Andamios, Vol. 5, no 9, Diciembre 2008, pp. 157-181.

KUKLYS, W., Amartya Sen's Capability Approach. Theoretical Insights and Empirical Application, Springer-Verlag, Berlin, Heidelberg, 2005. 
LEACH, M. et al., Environmental Entitlements: a framework for understanding the institutional dynamics of environmental change, Discussion Paper 359, Institute of Development Studies, Brighton, 1997.

PEDRAJAS HERRERO, M., El desarrollo humano en la economía ética de Amartya Sen, Servei de Publicacions, Universitat de Valencia, 2006.

RAWLS J., A Theory of Justice, The Belknap Press of Harvard University Press, Cambridge, 2005.

SEN, A. K., Poverty and Famines: An Essay on Entitlement and Deprivation, Clarendon Press, Oxford, 1981.

- On Ethics \& Economics, Billing \& Sons Ltd., Worcester, 1984.

- Utilitarianism and beyond, Cambridge University Press, Cambridge, 1988.

- Gender and cooperative conflicts, en Persistent Inequalities: Women and World Development, Tinker, I. (Editor), Oxford University Press, New York, 1990.

— Inequality Reexamined, Harvard University Press, Cambridge, 1995.

- Bienestar, Justicia y Mercado, Ed. Paidós, I.C.E. de la Universidad Autónoma de Barcelona, Barcelona-Buenos Aires-México, 1997.

- Resources, values and development, First Harvard University Press, Cambridge, Massachusetts, 1997.

- Development as Freedom, First Anchor Books, New York, 2000.

- La démocratie des autres, Éditions Payot \& Rivages, Paris, 2005.

- The Idea of Justice, The Belknap Press of Harvard University Press, Cambridge, 2009. 